ORNL/TM-2018/12

CRADA/ NFE-16-06239

\title{
Optimizing Parameters for Post- Processing of Ti-6Al-4V Components Fabricated by Additive Manufacturing for Superior Performance
}

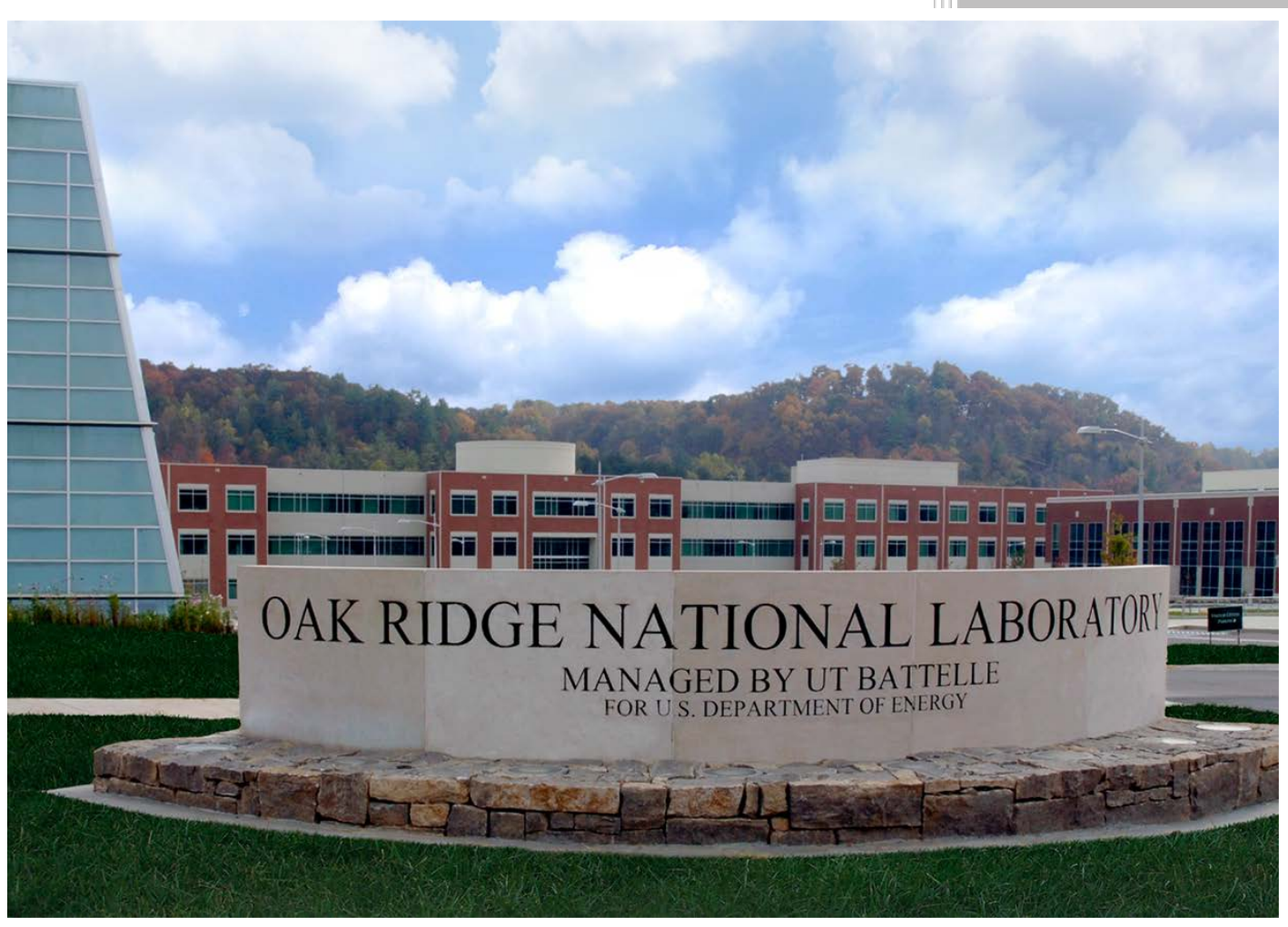

Peeyush Nandwana

January 10, 2018

CRADA FINAL REPORT NFE-16-06239

Approved for Public Release. Distribution is Unlimited. 


\title{
DOCUMENT AVAILABILITY
}

Reports produced after January 1, 1996, are generally available free via US Department of Energy (DOE) SciTech Connect.

Website http://www.osti.gov/scitech/

Reports produced before January 1, 1996, may be purchased by members of the public from the following source:

\author{
National Technical Information Service \\ 5285 Port Royal Road \\ Springfield, VA 22161 \\ Telephone 703-605-6000 (1-800-553-6847) \\ TDD 703-487-4639 \\ Fax 703-605-6900 \\ E-mail info@ntis.gov \\ Website http://www.ntis.gov/help/ordermethods.aspx
}

Reports are available to DOE employees, DOE contractors, Energy Technology Data Exchange representatives, and International Nuclear Information System representatives from the following source:

Office of Scientific and Technical Information

PO Box 62

Oak Ridge, TN 37831

Telephone 865-576-8401

Fax 865-576-5728

E-mail reports@osti.gov

Website http://www.osti.gov/contact.html

This report was prepared as an account of work sponsored by an agency of the United States Government. Neither the United States Government nor any agency thereof, nor any of their employees, makes any warranty, express or implied, or assumes any legal liability or responsibility for the accuracy, completeness, or usefulness of any information, apparatus, product, or process disclosed, or represents that its use would not infringe privately owned rights. Reference herein to any specific commercial product, process, or service by trade name, trademark, manufacturer, or otherwise, does not necessarily constitute or imply its endorsement, recommendation, or favoring by the United States Government or any agency thereof. The views and opinions of authors expressed herein do not necessarily state or reflect those of the United States Government or any agency thereof. 
ORNL/TM-2018/12

CRADA/ NFE-16-06239

Materials Science and Technology Division

Advanced Manufacturing Office

\title{
Optimizing Parameters for Post-Processing of Ti-6Al-4V Components Fabricated by Additive Manufacturing for Superior Performance
}

\author{
Authors \\ Peeyush Nandwana (ORNL) \\ Ryan Dehoff (ORNL) \\ Sean Yoder (ORNL) \\ William Peter (ORNL) \\ Magnus Ahlfors (Quintus Technologies, Inc.)
}

Date Published:

January 10, 2018

Prepared by

OAK RIDGE NATIONAL LABORATORY

Oak Ridge, Tennessee 37831-6283

managed by

UT-BATTELLE, LLC

for the

US DEPARTMENT OF ENERGY

under contract DE-AC05-00OR22725

Approved For Public Release 


\section{CONTENTS}

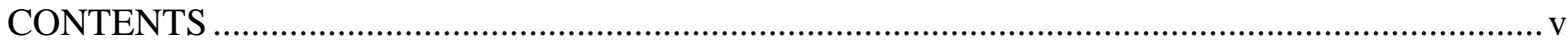

LIST OF FIGURES

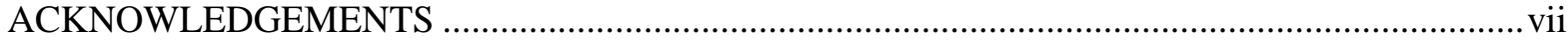

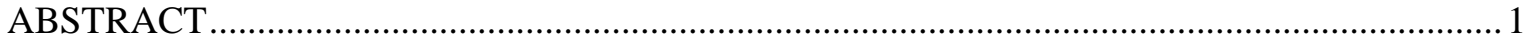

1. OPTIMIZING PARAMETERS FOR POST-PROCESSING OF TI-6AL-4V COMPONENTS

FABRICATED BY ADDITIVE MANUFACTURING FOR SUPERIOR PERFORMANCE......... 1

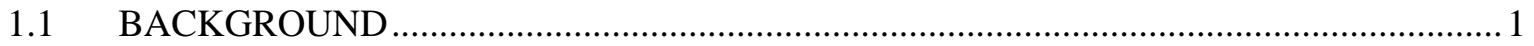

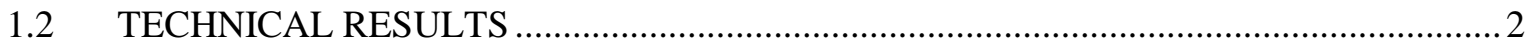

1.2.1 Impact of Powder Feedstock on Mechanical Properties ........................................................ 4

1.2.2 Effect of Hot Isostatic Pressing Parameters on Mechanical Properties ................................... 5

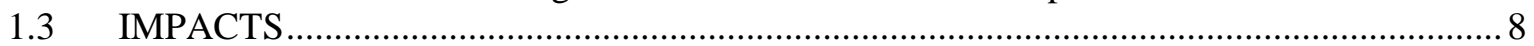

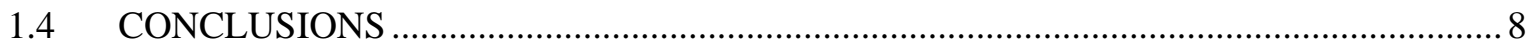

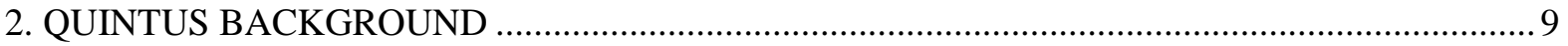




\section{LIST OF FIGURES}

Figure 1 shows IPF map and pole figure of as-fabricated sample (a \& b), IPF and pole figure of HIP'ed sample (c \& d), S-N plot comparing the fatigue behavior under as-fabricated and HIP'ed conditions (e), fractograph showing failure origin at a pore in as-fabricated sample (f), and fractograph showing faceted fracture in HIP'ed sample (g) ........................................................... 2

Figure 2 shows the build layout used in the study......................................................................... 3

Figure 3 presents the representative microstructure of samples from the three feedstocks.................. 4

Figure 4 compares the tensile (a) and HCF behavior (b) of samples fabricated from the three powder

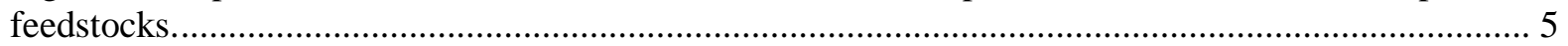

Figure 5 shows the sub-transus and super-transus HIP cycles used in the study................................ 6 Figure 6 compares and contrasts the microstructures under different processing and post-processing

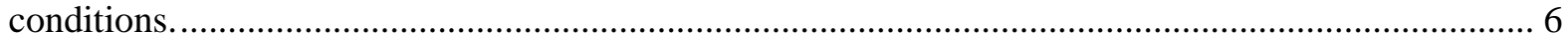

Figure 7 compares the UTS values of sub-transus HIP, super-transus HIP, and as-fabricated samples.7 Figure 8 shows the HCF behavior of as-fabricated, sub-transus, and super-transus HIP'ed samples along horizontal and vertical directions. 


\section{ACKNOWLEDGEMENTS}

This CRADA NFE-16-06239 was conducted as a Technical Collaboration project within the Oak Ridge National Laboratory (ORNL) Manufacturing Demonstration Facility (MDF) sponsored by the US Department of Energy Advanced Manufacturing Office (CPS Agreement Number 24761).

Opportunities for MDF technical collaborations are listed in the announcement "Manufacturing Demonstration Facility Technology Collaborations for US Manufacturers in Advanced Manufacturing and Materials Technologies” posted at http://web.ornl.gov/sci/manufacturing/docs/FBO-ORNL-MDF-2013-2.pdf. The goal of technical collaborations is to engage industry partners to participate in short-term, collaborative projects within the Manufacturing Demonstration Facility (MDF) to assess applicability and of new energy efficient manufacturing technologies. Research sponsored by the U.S. Department of Energy, Office of Energy Efficiency and Renewable Energy, Advanced Manufacturing Office, under contract DE-AC0500OR22725 with UT-Battelle, LLC. 



\begin{abstract}
ORNL worked with Quintus Technologies to develop new hot isostatic pressing parameters for Ti$6 \mathrm{Al}-4 \mathrm{~V}$ components fabricated via Arcam electron beam melting. These parameters result in isotropic tensile behavior compared to the conventional hot isostatic press HIP parameters that result in anisotropic tensile properties depending on the build direction. Furthermore, an improvement in fatigue behavior was observed.

\section{OPTIMIZING PARAMETERS FOR POST-PROCESSING OF TI-6AL-4V COMPONENTS FABRICATED BY ADDITIVE MANUFACTURING FOR SUPERIOR PERFORMANCE}

This phase 2 technical collaboration project (MDF-TC-2016-014) was started on July 01, 2016 and was completed on December 29, 2017. The collaboration partner Quintus Technologies is a small business. In this project, the partners used a proprietary rapid quench hot isostatic press (HIP) developed by Quintus Technologies to demonstrate isotropic tensile behavior of electron beam melted Ti-6Al-4V.

\title{
1.1 BACKGROUND
}

Quintus Technologies is a small business that specializes in fabrication of systems for hot isostatic pressing (HIP). In the HIP industry, it is typical to cool the samples after a HIP treatment either via furnace cooling or via rapid cooling to minimize the cycle time. In these cases, the typical cooling rates are between $5^{\circ} \mathrm{C} / \mathrm{min}$ to $100^{\circ} \mathrm{C} / \mathrm{min}$. For metallic materials, these are relatively slow cooling rates that could result in significant microstructural coarsening, especially in titanium alloys such as Ti-6Al-4V. In additive manufacturing (AM) of Ti-6Al-4V, there are added processing challenges such as porosity and formation of columnar grains. This results in $\alpha$ phase texture during $\beta \rightarrow \alpha$ phase transformation. Researchers have demonstrated that $\alpha$ phase texture can result in anisotropic material properties [1,2]. This is especially challenging since AM is used to fabricated complex shapes wherein the texture may significantly vary from one location to another in a build. Although, a standard HIP cycle $\left(920^{\circ} \mathrm{C}-\right.$ $100 \mathrm{MPa}-2 \mathrm{hrs}$ which is based on casting literature on Ti-6Al-4V), referred to as sub-transus HIP henceforth, is used to close the porosity, it has negligible impact on the $\beta$ grain structure or the texture. In fact, it strengthens the texture as discussed by Shui et al [3]. Thus, Oak Ridge National Laboratory's (ORNL) Manufacturing Demonstration Technology (MDF) partnered with Quintus Technologies (formerly Avure Technologies Inc.) for a technical collaboration to explore alternate post-processing routes to close the as-fabricated porosity and modify the microstructure in the same HIP cycle. 


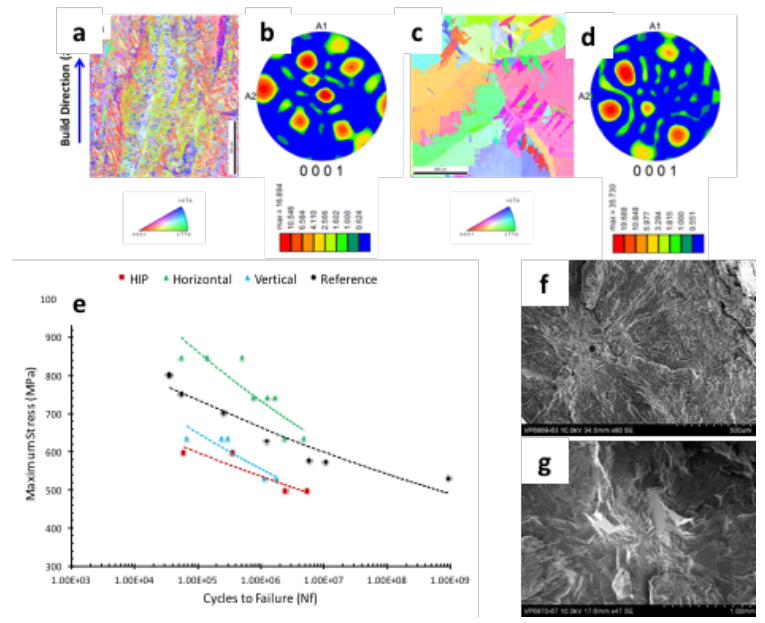

Figure 1 shows inverse pole figure (IPF) map and pole figure of as-fabricated sample (a \& b), IPF and pole figure of HIP'ed sample (c \& d), S-N plot comparing the fatigue behavior under as-fabricated and HIP'ed conditions (e), fractograph showing failure origin at a pore in as-fabricated sample (f), and fractograph showing faceted fracture in HIP'ed sample (g)

In the Phase 1 technical collaboration between ORNL and Quintus Technologies, a new HIP cycle $\left(1100^{\circ} \mathrm{C}-100 \mathrm{MPa}-2 \mathrm{~h}\right)$, referred to as super-transus HIP henceforth, was developed for modifying the microstructure of electron beam melted (EBM) Ti-6Al-4V. The results of Phase 1 are summarized in Fig. 1. To be noted is the presence of columnar $\beta$ grains decorated by grain boundary $\alpha$ (Fig. 1a) along with a Basal/Transverse $(\mathrm{B} / \mathrm{T}) \alpha$ phase texture in the as fabricated condition (Fig. 1b). On subsequent HIP'ing the $\beta$ grains become equiaxed and the $\alpha$ phase texture is very different from the as-fabricated $\mathrm{B} / \mathrm{T}$ texture as seen in Figs. 1c and 1d respectively. However, the fatigue strength in the super-transus HIP'ed condition was lower than the fatigue strength of as-fabricated sample tested along transverse testing direction and comparable to the as-fabricated sample tested along the build direction (Fig. 1e). The dominant failure mechanism was initiation at the pores in as-fabricated condition (Fig. 1f) and faceted fracture due to the presence of large $\alpha$ colonies in the HIP'ed samples (Fig. 1g). This lower fatigue strength was due to the formation of large $\alpha$ colonies resulting from lower cooling rates during HIP. As a result, the Phase 2 of technical collaboration resulted in Quintus Technologies installing a rapid quench HIP system (QIH 9 URQ) at ORNL's MDF that is one of a kind in North America.

Phase 2 focused on using the rapid quench HIP system to improve the mechanical properties of EBM Ti-6Al-4V that would allow Quintus to develop a business case for developing rapid quench HIP vessels for closing porosity and tailoring the microstructure of additively manufactured components. The hypothesis going into Phase 2 was to use the unique HIP cycle developed in Phase 1 coupled with rapid quench to demonstrate that the mechanical properties of EBM Ti-6Al-4V can be made isotropic via post processing compared to those in as-deposited state. The following sections contain detailed results of the study.

\subsection{TECHNICAL RESULTS}

Phase 2 began with procurement and evaluation of three different powder feedstocks from different vendors. The powders were made via plasma rotating electrode process (PREP), plasma atomization (PA), and plasma wire atomization (PWA) in no particular order. The powders were characterized for physical characteristics like flowability and apparent density in accordance with ASTM B213-03 and 
ASTM B212-99 respectively [4,5]. Furthermore, powder size distribution (PSD) was measured using a Horiba LA-950 Laser Particle Analyzer. Standard Arcam test samples (Shown in Figure 2) were fabricated in an Arcam Q10 EBM machine running software version 5.0.62 to keep the process parameters unchanged between the different powders. This was done to minimize any variability resulting from processing. The fabricated samples were subjected to chemical analysis. The powder characteristics and chemistry data of the builds is summarized in Table 1.

Table 1 summarizes the powder characteristics and chemistry of as-fabricated samples

\begin{tabular}{|c|c|c|c|}
\hline & Powder A & Powder B & Powder C \\
\hline \multicolumn{4}{|c|}{ Powder Characterization } \\
\hline Flowability (s/50g) & $24.50 \pm 0.40$ & $25.88 \pm 28$ & $24.08 \pm 0.20$ \\
\hline Apparent Density (g/cc) & $2.44 \pm 0.01$ & $2.61 \pm 0.01$ & $2.60 \pm 0.00$ \\
\hline $\mathrm{D}_{10}(\mu \mathrm{m})$ & 55.0 & 71.4 & 62.2 \\
\hline $\mathrm{D}_{50}(\mu \mathrm{m})$ & 73.9 & 90.2 & 80.8 \\
\hline $\mathrm{D}_{90}(\mu \mathrm{m})$ & 91.8 & 97.9 & 95.6 \\
\hline \multicolumn{4}{|c|}{ Build Chemistry } \\
\hline Aluminum (weight\%) & 5.78 & 5.87 & 6.26 \\
\hline Vanadium (weight\%) & 3.90 & 4.31 & 4.07 \\
\hline Oxygen (weight\%) & 0.194 & 0.188 & 0.140 \\
\hline Titanium (weight\%) & Balance & Balance & Balance \\
\hline
\end{tabular}

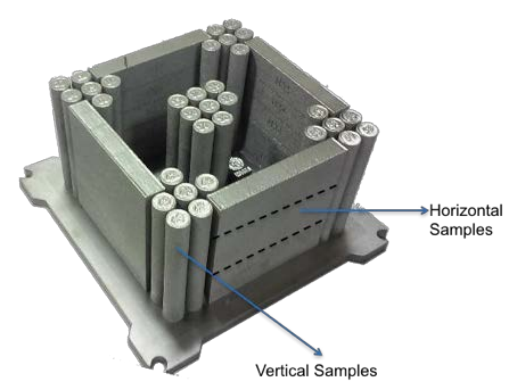

Figure 2 shows the build layout used in the study.

The samples were tested in both horizontal and vertical build orientations. As shown in Fig. 2 horizontal refers to the case wherein loading direction is perpendicular (transverse) to the build direction whereas in case vertical samples (longitudinal), the loading direction is parallel to the build direction. The samples tested under transverse loading have an " $\mathrm{H}$ " designation followed by a number whereas vertical samples have only numbers as markers. Following fabrication, some samples were tested for tensile and fatigue behavior in as-fabricated condition. Based on the mechanical behavior in the as-fabricated condition, samples from one specific powder feedstock were chosen for sub-transus 
and super-transus HIP and were tested for tensile and fatigue behavior. Sub-transus HIP was conducted as a baseline since it is the current industry standard for HIP of AM Ti-6Al-4V parts. In all cases, room temperature tensile tests were conducted per ASTM E-08-13a standard. High cycle fatigue (HCF) testing was performed at a stress ratio of $\mathrm{R}=0.1$ and a frequency of $20 \mathrm{~Hz}$. The samples were fabricated per ASTM E466-15 standard. The runout was considered at 5,000,000 cycles. The following subsections discuss the impact of powder feedstock on tensile and fatigue behavior following which the effect of HIP parameters on microstructure and mechanical properties is discussed.

\subsubsection{IMPACT OF POWDER FEEDSTOCK ON MECHANICAL PROPERTIES}

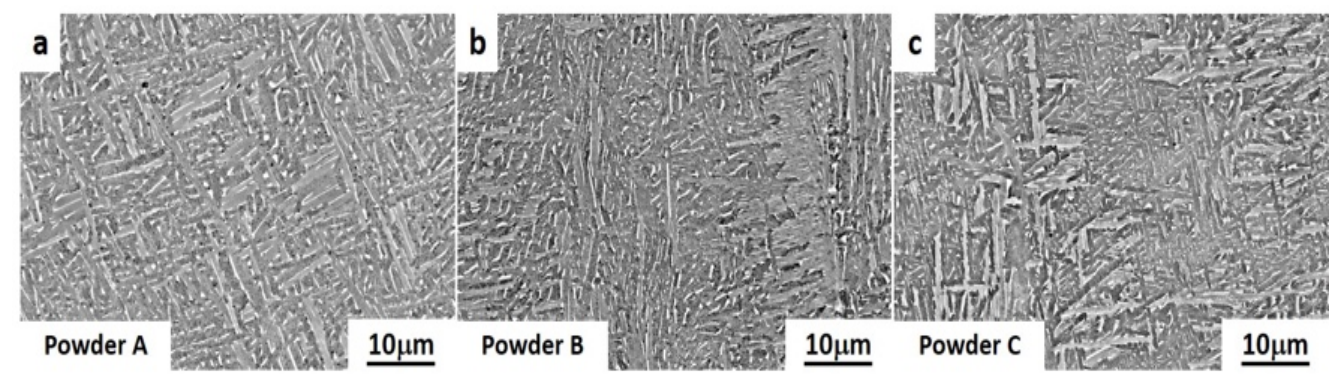

Figure 3 presents the representative microstructure of samples from the three feedstocks.

Powder feedstock plays a crucial role on the microstructure and final material properties of EBM samples. Representative microstructures from the three different powder feedstock builds are shown in Fig. 3. The microstructure is an $\alpha / \beta$ structure consisting of fine basket weave $\alpha$ laths along with grain boundary $\alpha$ distributed in a colony fashion. These microstructural features are typical of EBM fabricated Ti-6Al-4V and have been discussed in detail by other researchers [6-8]. Thickness measurements were performed on $\alpha$ laths via manual measurements by averaging measurements over multiple laths. It was observed that powder A had the coarsest laths with a thickness of about $0.62 \mu \mathrm{m}$ whereas samples from Powders B and C had similar lath thicknesses at $0.56 \mu \mathrm{m}$ and $0.57 \mu \mathrm{m}$ respectively. The slightly coarser $\alpha$ laths in builds from Powder A maybe explained based on the lower apparent density of these powders. This can possibly result in the powder bed retaining more heat thus coarsening the laths. In contrast, the other two powders have similar apparent density and the resulting builds have similar lath thicknesses. These differences in lath thicknesses were expected to manifest as differences in tensile and fatigue properties of the samples.

Fig. 4 (a) summarizes the tensile behavior of builds from all three powders. As expected, the builds from Powder A have the lowest yield (YS) and ultimate tensile strength (UTS) values owing to their coarser $\alpha$ laths that is about 40-50MPa lower than those of samples fabricated from Powders B and $\mathrm{C}$, which have similar yield and UTS values. Fig. 4 (b) presents the HCF plots for samples fabricated from the three powder feedstocks along vertical and horizontal loading directions. To be noted is that all samples display anisotropic fatigue strength along the build directions. This may possibly be attributed to the effect of texture on material properties as discussed earlier in Fig. 1. Interestingly, Powder A has higher fatigue strength compared to Powders B and C, despite having a lower yield strength that appears to be counter-intuitive based on the fact that fatigue strength is approximately proportional to the yield strength. In-situ near infrared images were used to gain insights towards the higher fatigue strength of Powder A and it was found that it had lower number of pores per layer compared to samples fabricated from Powder B that had about 3-4x the number of pores on a layer-by-layer basis. Since HCF is dominated by crack initiation, higher porosity results in poorer fatigue performance. The near infrared analysis for porosity detection is beyond the scope of the current report. 

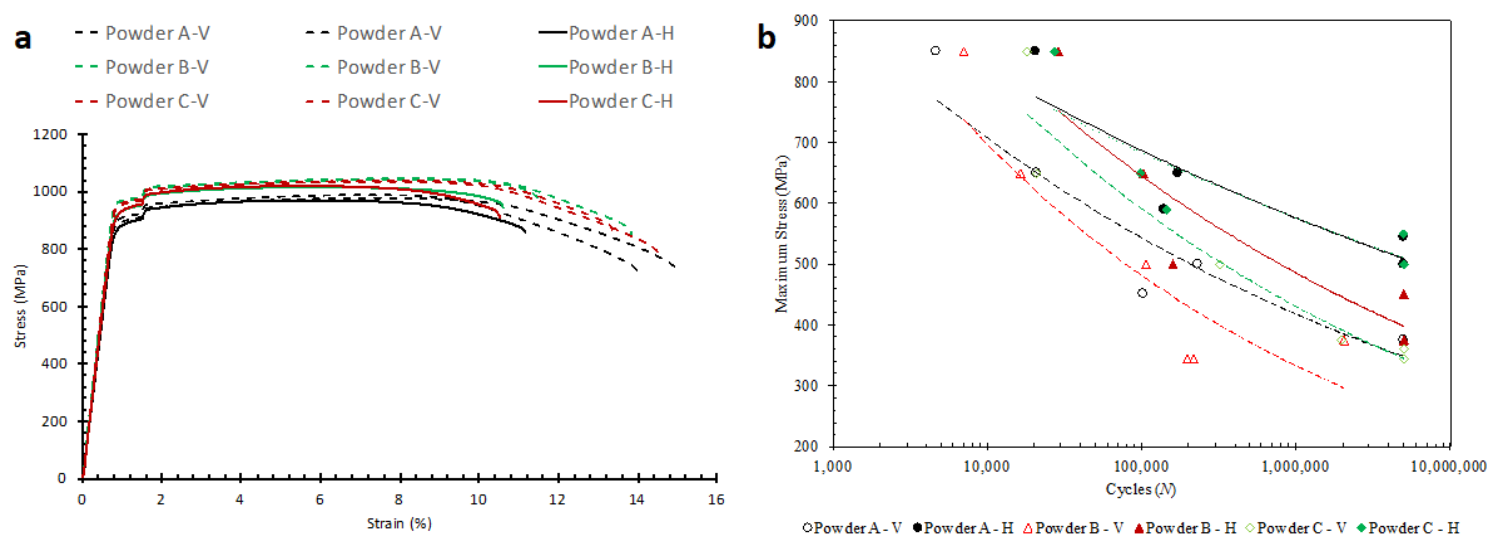

Figure 4 compares the tensile (a) and HCF behavior (b) of samples fabricated from the three powder feedstocks.

\subsubsection{EFFECT OF HOT ISOSTATIC PRESSING PARAMETERS ON MECHANICAL PROPERTIES}

Based on the HCF results, samples fabricated from Powder B were selected for studying the impact of HIP in manipulating the texture and associated mechanical properties. The rationale behind this selection was that the lower initial porosity highlights the role of texture in anisotropic behavior thus making pre-and post-HIP comparisons more meaningful. One set of samples was subjected to the standard sub-transus HIP cycle $\left(920^{\circ} \mathrm{C}-100 \mathrm{MPa}-2 \mathrm{~h}\right)$ followed by normal cooling. The second set was subjected to super-transus HIP $\left(1100^{\circ} \mathrm{C}-100 \mathrm{MPa}-2 \mathrm{~h}\right)$ followed by a rapid quench that resulted in a cooling rate of about $750^{\circ} \mathrm{C} / \mathrm{min}$. The pressure and time were unchanged to understand only the effect 
of temperature and cooling rate on subsequent material properties after HIP. Fig. 5 compares the two HIP cycles used in the study. The difference in cooling rates is evident in the figure.

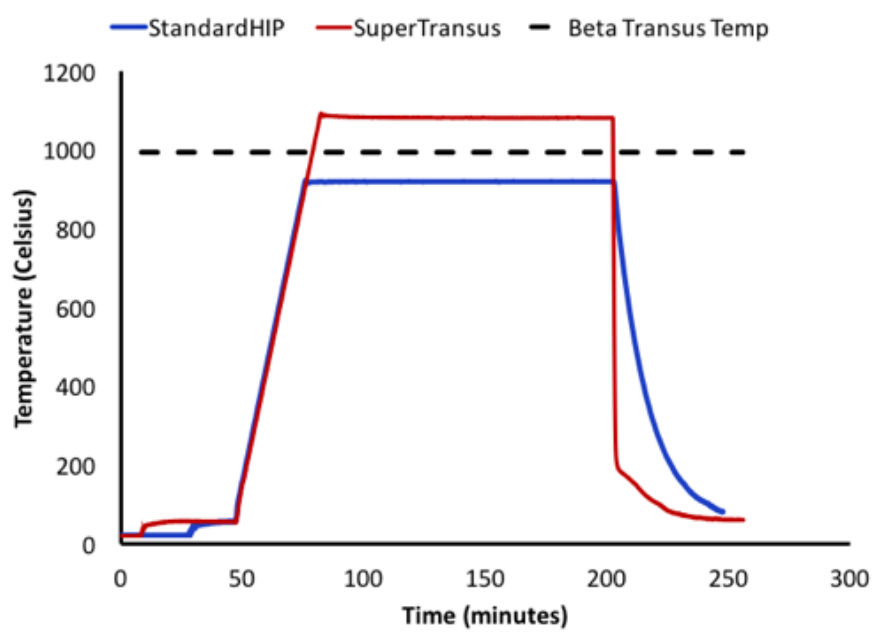

Figure 5 shows the sub-transus and super-transus HIP cycles used in the study.

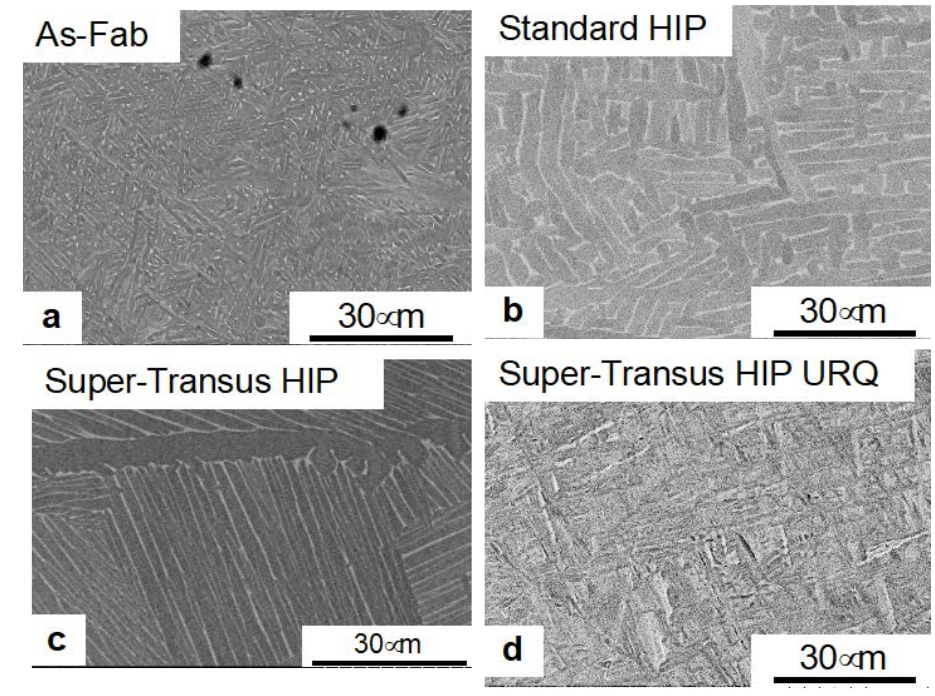

Figure 6 compares and contrasts the microstructures under different processing and post-processing conditions.

Fig. 6 compares and contrasts the microstructures under different processing and post-processing conditions. To be noted is the coarsening of $\alpha$ laths during standard HIP cycle (Fig. 6b). However, the basket weave nature of $\alpha$ laths is preserved from the as-fabricated sample (Fig. 5a). On conducting super-transus HIP without the use of a rapid quench HIP vessel, the $\alpha$ becomes coarser and the distribution changes from basket weave to colony (Fig. 5c). This is because all $\alpha$ is dissolved on heating the sample above $\beta$-transus. On slower cooling, grain boundary $\alpha$ precipitates on prior $\beta$ grain boundaries and nucleates a colony microstructure as the temperature is reduced further. Fig. 6 (d) shows the impact of using a rapid quench HIP vessel on microstructure evolution after super-transus HIP. It can be seen that a fine basket weave microstructure is obtained akin to the as-fabricated microstructure, 
but with possibly lesser degree of elemental partitioning and slightly coarser $\alpha$. This is expected to result in higher tensile strength compared to the sub-transus HIP. The tensile data for Powder B as a function of processing and post-processing condition is summarized in Fig. 7 per their UTS values. It can be seen that the super-transus HIP homogenizes the UTS irrespective of loading direction. On the other hand, the sub-transus HIP process results in retaining and to an extent strengthening the anisotropic material behavior. This is due to strengthening of $\beta$-texture on sub-transus HIP and has been discussed by Shui et al [3]. It can be seen that due to the rapid cooling rates and finer a, the supertransus HIP'ed samples have a higher UTS compared to conventionally HIP'ed samples. However, it is about 2-3\% lower than that of the as-fabricated samples. To be noted is the isotropy of UTS after subjecting the samples to super-transus HIP cycle followed by rapid quench. The samples were tested under fatigue loading under the above discussed process conditions. Figure 8 summarizes the findings of HCF testing.

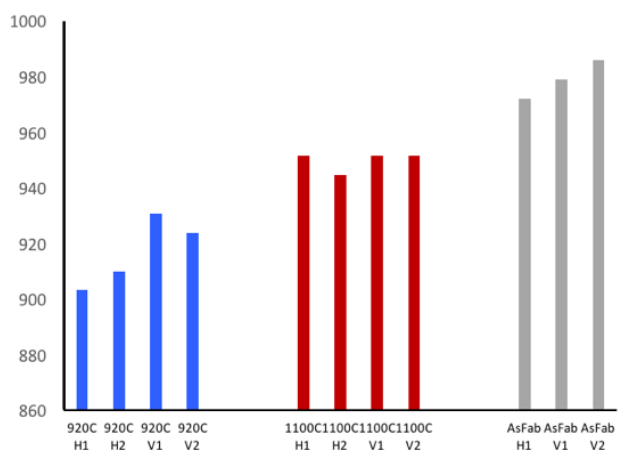

Figure 7 compares the UTS values (MPa) of sub-transus HIP, super-transus HIP, and as-fabricated samples.

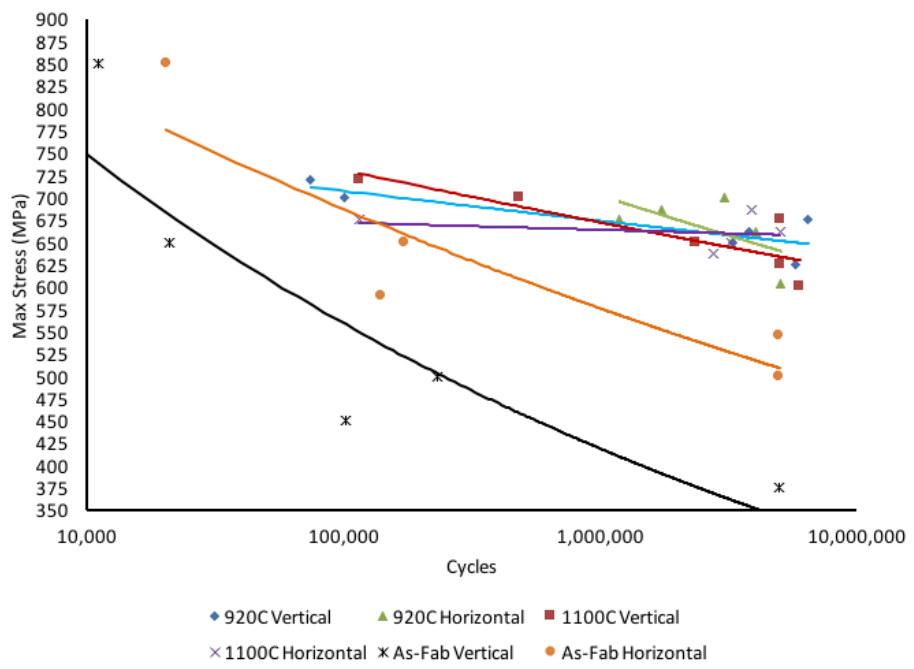

Figure 8 shows the HCF behavior of as-fabricated, sub-transus, and super-transus HIP'ed samples along horizontal and vertical directions.

It can be noted that HIP'ing improves the fatigue strength and significantly reduces the scatter in data irrespective of the HIP cycle. However, despite the use of HIP there still remains some scatter in the samples for both sub-transus and super-transus HIP. Also, the anisotropy component is preserved, 
even for the super-transus HIP samples. Based on the S-N plot, it appears that despite HIP'ing, not all pores are annihilated, thus causing a scatter in the data. In some cases, it can be seen that the sample sustains more cycles at higher stress levels and that can happen only in presence of defects where the failure initiation can be stochastic. Compared to as-fabricated samples, the HIP'ed samples have significantly less porosity and thus the likelihood of retaining a pore in the machined test sample in the gage section is very low thereby having a stronger impact on variation in cycles to failure. This requires for new HIP cycles to be developed for the AM components, possibly by using higher temperature, pressure and times and generate statistical fatigue curves to better understand the implications of HIP'ing on the fatigue behavior of Ti-6Al-4V. While, the tensile behavior is promising for the supertransus HIP in terms of improving strength and reducing the anisotropy compared to standard HIP cycle, the use of Ti-6Al-4V primarily as a fatigue alloy mandates the development of new HIP cycles and generating the fatigue curves at different stress levels. The efficacy of super-transus HIP can be further extended to other AM techniques in an attempt to make the properties more predictable independent of the AM technology used thereby allowing for better design of components. This predictability in properties is crucial towards accelerating the acceptance of AM as a full-scale production technology.

\subsection{IMPACTS}

In the current state of the technology, additively made components inherently contain porosity that can either be process induced or result from pores in the original powder feedstock. Therefore, Hot Isostatic Pressing is currently a requirement, especially in aerospace, biomedical, and gas turbine industries that involve rotating components. Along with closing the porosity, HIP can potentially also be used to alter the as-fabricated microstructures and textures. The challenge with most HIP vessels is that they can be used to close porosity but not influence the microstructure since the cooling rate is often to low and not controllable. Thus, a secondary step has to be added for additional heat treatments. During these heat treatments, the pores can reopen and have been discussed in literature. In our collaboration with Quintus Technologies (Phase 1 and Phase 2) ORNL developed a new HIP cycle to modify the microstructure of EBM Ti-6Al-4V and breakdown the $\alpha$ phase texture. The QIH 9 press allowed us to manipulate the microstructure to improve the tensile properties of the super-transus HIP'ed samples and reduce the anisotropy compared to the standard HIP cycle. These heat treatments are conducted under pressure and hence the likelihood of reopening of porosity is significantly lower. The process also reduces the downtime and saves energy by completing the HIP and heat-treatment in a single cycle.

Our results indicate that the existing HIP cycles that are based on casting literature, are not sufficient to close all porosity, Hence even after HIP'ing there is a small degree of scatter in the mechanical properties. Thus, going forward Quintus Technologies and ORNL will partner to develop HIP cycles for AM Ti-6Al-4V. Furthermore, the testing and HIP cycles will be extended to other AM techniques such as laser powder bed fusion, wire based large scale AM. The success of this study will propel the field towards developing rapid quench machines for larger sections and dedicated to AM alloys. Finally, going forward, studies will be conducted on HIP'ing of non-weldable Ni base superalloys that are sensitive to cooling rate. Faster cooling rates can be used to prevent the $\gamma^{\prime}$ from coarsening and reduce the potential for cracking while improving mechanical properties.

\subsection{CONCLUSIONS}

In conclusion, the technical collaboration between ORNL and Quintus Technologies demonstrated the potential and need for developing new HIP cycles in tandem with more capable HIP systems. We developed a new HIP cycle and demonstrated that the material properties can be made more isotropic for Ti-6Al-4V via use of super-transus HIP. Further, the material strength was retained by using the 
rapid quench enabled HIP vessel that results in precipitation of fine scale $\alpha$. However, it was also found out that both the standard and super-transus HIP cycles cannot completely heal the porosity with the existing parameters. Thus, moving forward parameter optimization studies need to be conducted along with fatigue testing to establish the role of different HIP cycles on fatigue response as a function of loading direction. This will allow the HIP cycle to be extended to Ti-6Al-4V components fabricated via AM technologies other than EBM that will be crucial for adoption of AM as a wide scale production technique. Finally, the rapid quench enabled QIH 9 press opens the doors for successful HIP'ing of non-weldable Ni base alloys to retain and improve upon the as-fabricated material properties.

\section{QUINTUS BACKGROUND}

Quintus Technologies specializes in the design, manufacture, installation, and support of high pressure systems for sheet metal forming and densification of advanced materials and critical industrial components. Headquartered in Västeräs, Sweden, and represented in 35 countries worldwide, the company is the world leader in high pressure technology and has delivered more than 1,800 systems to customers across the globe within industries such as aerospace, automotive, energy, and medical implants. 